УДК 346.6, 336.225.4

DOI https://doi.org/10.32837/apdp.v0i83.129

И. С. Пирога

\title{
СТРУКТУРА ДОБАВЛЕННОЙ СТОИМОСТИ И ОПТИМИЗАЦИЯ НАЛОГОВОЙ БАЗЫ
}

Постановка задания. В Украине бытует мнение, что рыночная экономика является саморегулирующейся системой, которая автоматически обеспечивает оптимальные темпы развития экономики, повышение производительности труда, технического и технологического уровней экономики, занятости населения и так далее. Эта мысль совершенно ошибочна хотя бы потому, что все сферы жизни общества (и экономика в первую очередь) регулируются законами, которые принимает законодательная власть (она же должна обеспечить сопровождение, то есть анализировать эффективность и вносить соответствующие изменения), а применение этих законов осуществляет исполнительная и судебная власть. Итак, конечный результат зависит от эффективности работы всех ветвей власти. Конечно, основную роль играет законодательная власть, тем более, что она назначает и исполнительную и судебную.

Социальная эффективность экономики выражает степень удовлетворения личных потребностей человека и создание условий для ее всестороннего развития. Она показывает, насколько хозяйственная деятельность соответствует интересам человека. Социально ориентированный рынок предполагает не только механизмы государственного регулирования, но и выполнения государством функции социальной защиты населения.

Государственное регулирование экономической и социальной эффективности экономики заключается в обеспечении оценки и регулирования двух показателей: вновь созданная добавленная стоимость и пропорции ее распределения. Вновь созданная добавленная стоимость определяет экономическую әффективность функционирования экономики, а пропорции ее распределения - социальные стандарты в государстве. Регулирование этих показателей предполагает проведение активной политики: бюджетной, налоговой, таможенной, финансово-кредитной, денежной, амортизационной, инвестиционной, антикризисной, антициклической, антимонопольной.

Бюджетная, налоговая, денежно-кредитная (монетарная) и валютная политика в Украине формируется обособленно, а не как подсистемы единой финансовой политики. Главной задачей финансовой политики является поиск и внедрение оптимальной модели перераспределения финансовых ресурсов с целью обеспечения устойчивого развития производства, стимулирования предпринимательской и инновационной деятельности, повышение уровня занятости и социальной защиты населения.

Государственная амортизационная политика является важным фактором активизации инвестиционной деятельности предприятий. Правительства развитых стран мира активно используют ускоренную амортизацию и амортизационные 
льготы с целью регулирования скорости оборота основного капитала, интенсификации процесса его воспроизводства, внедрения достижений научно-технического прогресса, стимулирования нововведений и роста конкурентоспособности национальных предприятий.

Целью статьи является обоснование структуры добавленной стоимости и оптимальных способов налогообложения ее составляющих элементов для повышения экономической и социальной эффективности экономики.

Основное исследование. Добавленная стоимость - это суммарная стоимость, созданная на всех этапах производственного и реализационного циклов на пути товара к конечному потребителю. Приведенное определение понятия «добавленная стоимость» является общепринятым. Однако структура добавленной стоимости (ее составляющие элементы) трактуются по-разному. Определение составляющих элементов добавленной стоимости имеет важное значение, поскольку добавленная стоимость определяет налоговую базу универсального акциза - налога на добавленную стоимость (НДС), который полностью включается в цену товара. Включение составляющих, которые не представляют добавленной стоимости, искусственно увеличивает налоговую базу НДС, что эквивалентно повышению эффективной ставки налога, увеличивает цену товаров/услуг для конечного потребителя, а, следовательно, и снижает покупательную способность, искусственно увеличивает размер ВВП. Если нет точного определения составляющих добавленной стоимости, возникают споры при исчислении налогооблагаемой базы, а, следовательно, и суммы налога, подлежащей уплате и/или возмещению.

Полную стоимость на каждом этапе производственного цикла удобно разделить на две составляющие: добавленная стоимость, созданная на этом этапе, плюс добавленная стоимость, созданная на всех предыдущих этапах производственного и реализационного цикла. Последнюю составляющую обычно трактуют как затраты производства. Затраты - это добавленная стоимость, созданная на всех предыдущих этапах производственного цикла. К затратам производства относят все, что использовано в производстве (стоимость сырья, материалов, комплектующих и так далее).

Для вычисления добавленной стоимости, созданной на конкретной стадии производственного цикла, надо суммировать ее составляющие. Вопрос о составляющих добавленной стоимости на сегодняшний день практически не решен. Поэтому добавленная стоимость может включать различные составляющие. Элементами добавленной стоимости часто считают начисленную амортизацию, фонд оплаты труда персонала, чистую прибыль, налоги, затраты на социальное обеспечение и коммерческие активы [1].

Для определения добавленной стоимости, созданной на отдельной стадии производственного цикла, вышеприведенная трактовка содержит лишние составляющие. Совсем некстати включать в состав добавленной стоимости налоги. Прямые налоги являются составляющей добавленной стоимости, то есть это часть добавленной стоимости. Какая часть добавленной стоимости производится в виде налога, а какая остается в распоряжении производителя определяется Налоговым кодексом (НК). Для каждого вида прямых налогов доля отчисления разная. Косвенные налоги - это дополнительные начисления на добавленную стоимость, точно 
не создают никакой новой добавленной стоимости, изымаются с целью наполнения бюджета, а базой налогообложения для них является фонд потребления [2].

Безотносительно к степени детализации понятия «добавленная стоимость», в ее структуру нецелесообразно включать отдельные составляющие прибыли: налоги и чистую прибыль. Чистая прибыль - это прибыль, остающаяся в распоряжении предпринимателя после расчетов с бюджетом по налоговым и обязательным платежным обязательствам. А. Смит определял прибыль как доход на капитал, утверждая, что «доход, получаемый с капитала лицом, лично вкладывающим его в дело, называется прибылью» [3]. Д. Рикардо определял прибыль как часть стоимости, остающейся после вычета заработной платы [4]. В современной экономической теории прибыль трактуется как выраженный в денежной форме доход предпринимателя на вложенный капитал, как разница между общей выручкой от реализации (валовым доходом) и совокупными затратами фирмы. Затраты делятся на индивидуальные и общественные.

К индивидуальным затратам относят материальные затраты на сырье, материалы, комплектующие, инструменты, оборудование и тому подобное. Составной затрат также является амортизация. Амортизация - это механизм переноса стоимости оборудования на стоимость производимых/предоставляемых товаров/ услуг. Поскольку срок эффективной эксплуатации оборудования не ограничивается производством определенной партии товара, поэтому стоимость оборудования переносится на стоимость товара не сразу, а постепенно в течение всего срока эксплуатации. Амортизационные отчисления являются частью валовых затрат предприятия. В то же время они являются источником возмещения износа основных средств. Именно поэтому амортизационные отчисления являются важным фактором повышения эффективности общественного производства.

Амортизация - это механизм восстановления факторов производства. Начисленная амортизация сохраняется на отдельном счете, средства из которого предназначены для возмещения стоимости изношенного основного капитала. Пока начисленная амортизация хранится на специальном счете, амортизация представляет чистые затраты производства. Когда обновление основных фондов будет реально произведено независимо от способа восстановления (ремонт, реставрация или полная замена), используемые средства автоматически станут добавленной стоимостью. Однако, пока восстановление не проведено, амортизация может быть отнесена только к затратам производства. Эти затраты имеют такую же природу, как и затраты на инструменты и другое, менее стоящее оборудование, используемое в производственном процессе. Разница только в том, что стоимость оборудования, которое подлежит амортизации, относится на стоимость товаров по определенным нормам в зависимости от срока полезного использования, а стоимость инструментов - однократно. Итак, амортизация относится к затратам производства и определяет часть полной добавленной стоимости, созданной на предыдущих стадиях производственного цикла. На стадии использования оборудования амортизационные отчисления следует относить к затратам.

Общественные затраты связаны с обеспечением определенных условий для производства и реализации товаров или услуг, обеспечиваемых государством. Госу- 
дарство выполняет определенные функции, которые можно классифицировать по социальной значимости государственной деятельности на:

1) основные функции - важнейшие направления деятельности государства, имеющие приоритетное значение (защита прав и свобод человека, экономическая, социальная и так далее);

2) дополнительные (неосновные) функции - направления деятельности государства по осуществлению конкретных задач, которые имеют сопроводительный, вспомогательный или обслуживающий характер (управление персоналом, налогообложения, финансовый контроль).

Сегодня на издержки производства относят и фонд оплаты труда. Такое толкование не соответствует функции труда как фактора производства. Маржиналистская теория распределения факторных доходов выделяет четыре фактора производства, которым соответствуют такие формы доходов:

1) земля создает ренту;

2) капитал (инвестиционные ресурсы) - процент;

3) способность к предпринимательству - предпринимательский доход, нижней границей которого является нормальная прибыль;

4) труд - заработную плату.

Величина дохода на каждый из указанных выше факторов определяется предельным вкладом каждого в валовой доход фирмы. Такой принцип распределения доходов справедливый как для наемных работников, так и для землевладельцев, владельцев капитала, и людей, склонных к предпринимательству, поскольку он обеспечивает распределение дохода пропорционально вкладу каждого из факторов.

Для определения величины суммарной добавленной стоимости, созданной на определенном этапе производственного цикла, нецелесообразно выделять отдельно вклад каждого фактора. Достаточно выделить две составляющие: факторы, определяющие совокупный предпринимательский доход (капитал, способность к предпринимательству или земля) и заработную плату как доход на фактор производства - труд.

Государство, как один из участников создания добавленной стоимости, претендует на определенную долю в ее распределении. Способ привлечения финансовых ресурсов на выполнение функций государства может быть разным. Основная часть государственных расходов обеспечивается налогами. Поэтому в структуре добавленной стоимости должен быть отражен и вклад государства: то есть добавленная стоимость фактически подлежит распределению на три составляющие:

1. Фонд оплаты труда.

2. Прибыль предприятия.

3. Налоги.

Обязанность законодательной власти состоит в создании таких экономических законов, обеспечивающих наиболее эффективное распределение добавленной стоимости между фондом оплаты труда, прибылью субъектов хозяйствования и доходами государства. Поэтому способ распределения добавленной стоимости между субъектами производственного процесса может иметь разную степень детализации. Простейшая система распределения предполагает прямое участие государ- 
ства в распределении вновь созданной добавленной стоимости на каждой стадии производственного цикла. В этом случае цена на все товары / услуги строго определена: это сумма добавленной стоимости, созданной на всех этапах производственного и реализационного циклов на пути товаров / услуг к конечному потребителю.

Такая система распределения добавленной стоимости имеет как преимущества, так и недостатки. Главное преимущество в том, что обеспечивается паритет цен на товары/услуги и выравнивание рентабельности различных сфер вложения капитала. При установлении оптимальных пропорций распределения вновь созданной добавленной стоимости обеспечивается покупательная способность на товары/ услуги отечественного производства.

Главным недостатком такой системы распределения добавленной стоимости является то, что налоги выполняют только фискальную функцию, а государство лишается средств воздействия на экономику. Государство лишено возможности влияния на качество товаров/услуг, трудно обеспечить инновационный путь развития экономики, отсутствуют механизмы обеспечения приоритетного развития отдельных отраслей экономики. Для открытой рыночной экономики налоги играют основную роль в ее регулировании и выполняют следующие функции:

1) фискальную, которая заключается в мобилизации средств в распоряжение государства и формировании централизованных финансовых ресурсов для обеспечения выполнения государством своих функций;

2) регулирующую, которая реализуется через влияние налогов на эффективность деятельности предприятий;

3) стимулирующую, что предполагает оптимальный выбор объектов налогообложения, ставок налогов и льгот в целях стимулирования производства отдельных видов товаров.

Для включения регулирующей и стимулирующей функций налогов добавленная стоимость должна включать только две составляющие:

1) фонд оплаты труда;

2) прибыль предприятия.

Доходы государства формируются за счет налогообложения этих составляющих, то есть предусматривают только прямые налоги. В этом случае объектами налогообложения является фонд оплаты труда и прибыль. Причем для каждого объекта может устанавливаться несколько налогов. В Украине фонд оплаты труда является базой начисления социальных взносов, а разница между фондом оплаты труда и стянутыми взносами составляет доходы физических лиц, облагаемых дополнительно налогом на доходы физических лиц. Прибыль предприятия облагается налогом на прибыль. В зависимости от сферы использования, прибыль может освобождаться от налогообложения или облагаться налогом по разным ставкам. Так, от налогообложения может освобождаться часть прибыли, которая идет на финансирование НИОКР, приобретение инновационной техники, внедрение энергосберегающих технологий. Ставка налога установлена в размере пяти процентов для доходов в виде дивидендов по акциям и корпоративным правам, начисленных резидентами - плательщиками налога на прибыль предприятий (ст. 167.5.2 Налогового кодекса Украины (НКУ). 
Косвенные налоги НДС, акцизный налог и пошлины представляют собой надбавку к цене, которая начисляется по определенной ставке и включается в цену. Определение НДС в Налоговом Кодексе Украины фактически отсутствует. В соответствии с п.п. 197 п. 1 ст. 14 Налогового кодекса Украины «14.1.178. Налог на добавленную стоимость - косвенный налог, который начисляется и уплачивается в соответствии с нормами раздела V настоящего Кодекса». База налогообложения определена п. 1 ст. 188 «188.1. База налогообложения операций по поставке товаров/услуг определяется исходя из их договорной стоимости с учетом общегосударственных налогов и сборов ... ». Подпункт 1 п. 1 ст. 194 НКУ определяет порядок начисления НДС «194.1.1. Налог составляет 20 процентов, семь процентов базы налогообложения и прибавляется к цене товаров/услуг» .

Фактически НКУ дает возможность определить размер НДС, подлежащий уплате в государственный бюджет. Однако НКУ не определяет содержание этого понятия и его функции. Добавленная стоимость является фундаментальной характеристикой, определяющей эффективность экономики государства. Поскольку отсутствует структура добавленной стоимости, НДС рассматривается обособленно от налогообложения составляющих добавленной стоимости. Такой подход не позволяет оптимизировать налогооблагаемую базу и ставки основных налогов.

Доказана целесообразность определения добавленной стоимости в виде суммы двух составляющих - фонда оплаты труда и прибыли хозяйствующих субъектов. Никаких других составляющих добавленная стоимость включать не должна. Подобное определение добавленной стоимости находим в трудах лауреата Нобелевской премии П. Самуэльсона. Добавленная стоимость - это разница между стоимостью произведенных товаров и стоимостью материалов и сырья, использованных в ее производстве. Она включает заработную плату, процент и прибыль, добавленные к продукту фирмой или отраслью [5].

Такое толкование понятия «добавленная стоимость» целесообразно ввести в V раздел Налогового кодекса, изложив статью 185 в следующей редакции:

185.1 Объектом налогообложения является добавленная стоимость.

185.2 Добавленная стоимость определяется суммой факторных доходов - фонда оплаты труда и прибыли.

При такой трактовке добавленной стоимости можно точно определить ее величину (базу НДС), созданную на отдельном предприятии, в отдельном регионе, отрасли или экономике государства в целом. Одновременно определяются пропорции распределения добавленной стоимости между фондом оплаты труда и прибылью, что позволяет точно определить базу единого социального взноса и налогов на доходы физических лиц и на прибыль. Доля фонда оплаты труда в созданной добавленной стоимости дает числовую оценку степени социальной направленности экономики и выполнения государством нормы части четвертой статьи 13 Конституции Украины: «Государство обеспечивает защиту прав всех субъектов права собственности и хозяйствования, социальную направленность экономики. Все субъекты права собственности равны перед законом » .

Выводы. Добавленная стоимость определяет экономическую эффективность функционирования экономики, а пропорции ее распределения - социальные стан- 
дарты в государстве. Добавленная стоимость - это сумма факторных доходов фирмы - фонда оплаты труда и прибыли. Структура добавленной стоимости и пропорции ее составляющих определяют структуру налоговой системы, базы основных налогов (НДС, на доходы физических лиц, на прибыль), базу единого социального взноса, конкурентоспособность товаров/услуг, платежеспособный спрос.

\section{Jumepamypa}

1. Бабина Г.М. Добавленная стоимость - ключевой фактор финансового здоровья предприятия. Экономика и управление. 2014. № 3 (39). С. 42-45.

2. Пирога С.С., Пирога И.С. Двойственная природа объекта налогообложения НДС. Налоги и финансы. 2015. № 4. С. 15-20.

3. Смит А. Исследование о природе и причинах богатства народов: в 2-х т. Т. 1 / пер. с англ. П. Клюкина. М. : Эксмо, 2016. 496 с.

4. Рикардо Д. Начала политической экономии и налогового обложения. Сочинения: в 3-х т. / пер. П. Клюкина; под ред. Л. Амелехина. М. : Эксмо, 2007. 960 с.

5. Самуэльсон Пол Э., Вильям Д Нордхаус. Микроэкономика. 18-е изд. М. : Вильямс, 2008. 744 с.

\section{Аннотация}

Пирога И. С. Структура добавленной стоимости и оптимизация налоговой базы. - Статья.

Построение социально ориентированной рыночной экономики предусматривает регулирование двух показателей: величину добавленной стоимости и пропорции ее распределения в обществе. Вновь добавленная стоимость определяет эффективность функционирования экономики, а пропорции ее распределения - социальные стандарты в государстве. Структура добавленной стоимости до сих пор не имеет общепризнанной трактовки. В структуру добавленной стоимости безосновательно включаются лишние составляющие, которые искусственно увеличивают ее величину - налоговую базу НДС и цену товаров/услуг для конечных потребителей. Поскольку не определена структура добавленной стоимости, НДС рассматривается отдельно от налогообложения ее составляющих. Такой подход не позволяет оптимизировать налогооблагаемую базу и ставки основных налогов.

В статье обоснована структура добавленной стоимости, которая определяется суммой факторных доходов фирмы - фонда оплаты труда и прибыли, включающей предпринимательский доход, процент и ренту. Доля фонда оплаты труда в созданной добавленной стоимости дает числовую оценку степени социальной направленности экономики государства. Добавленная стоимость исчисляется как разница между стоимостью произведенных товаров и использованных материалов, сырья и начисленной амортизации. Добавленная стоимость и ее составляющие определяют основные объекты налогообложения, а, следовательно, и структуру налоговой системы. Добавленная стоимость является объектом налогообложения НДС, а ее составляющие определяют объекты налогообложения фонда оплаты труда и прибыли.

В Украине фонд оплаты труда является базой единого социального взноса, а разница фонда оплаты труда и начисленного социального взноса является базой налога на доходы физических лиц. Объективная оценка величины добавленной стоимости позволяет определить базу трех основных налогов (НДС, на доходы физических лиц, на прибыль), единого социального взноса и существенно упростить их администрирование.

Ключевые слова: добавленная стоимость, налог на добавленную стоимость (НДС), фонд оплаты труда, прибыль, объект налогообложения, налоговая база, факторы производства.

\section{Анотація}

Пирога I. С. Структура доданої вартості та оптимізація податкової бази. - Стаття.

Побудова соціально орієнтованої ринкової економіки передбачає регулювання двох показників: величину доданої вартості і пропорції її розподілу в суспільстві. Знову додана вартість визначає ефективність функціонування економіки, а пропорції її розподілу - соціальні стандарти в державі. Структура доданої вартості до сих пір не має загальновизнаної трактування. У структуру доданої вартості безпідставно включаються зайві складники, які штучно збільшують її величину - податкову базу ПДВ і ціну товарів/послуг для кінцевих споживачів. Оскільки не визначена структура доданої вартості, ПДВ розглядається окремо від оподаткування ії складників. Такий підхід не дозволяє оптимізувати базу оподаткування і ставки основних податків.

У статті обґрунтована структура доданої вартості, яка визначається сумою факторних доходів фірми - фонду оплати праці і прибутку, що включає підприємницький дохід, відсоток і ренту. Частка 
фонду оплати праці у створеній доданій вартості дає числову оцінку ступеня соціальної спрямованості економіки держави. Додана вартість обчислюється як різниця між вартістю вироблених товарів і використаних матеріалів, сировини і нарахованої амортизації. Додана вартість і їі складники визначають основні об'єкти оподаткування, а, отже, і структуру податкової системи. Додана вартість $€$ об’єктом оподаткування ПДВ, а її складники визначають об'єкти оподаткування фонду оплати праці і прибутку.

В Україні фонд оплати праці є базою єдиного соціального внеску, а різниця фонду оплати праці і нарахованого соціального внеску є базою податку на доходи фізичних осіб. Об'єктивна оцінка величини доданої вартості дозволяє визначити базу трьох основних податків (ПДВ, на доходи фізичних осіб, на прибуток), єдиного соціального внеску та істотно спростити їх адміністрування.

Ключові слова: додана вартість, податок на додану вартість (ПДВ), фонд оплати праці, прибуток, об’єкт оподаткування, податкова база, фактори виробництва.

\section{Summary}

Pyroha I.S. The structure of the added value and the optimization of the tax base. - Article.

The construction of a socially oriented market economy involves the regulation of two indicators: the value added and the proportion of its distribution in society. The newly added value determines the efficiency of the functioning of the economy and the proportions of its distribution - social standards in the state. The value-added structure does not currently have a generally accepted interpretation. Value-added structure unreasonably includes unnecessary components that artificially increase its value - the tax base of VAT and the price of goods/services for end consumers. As the structure of value added is not defined, VAT is considered separately from the taxation of its components.

This approach does not allow optimization of the tax base and basic tax rates. The article substantiates the value added structure, which is determined by the sum of factor income of the firm - payroll and profit, which includes entrepreneurial income, interest and rent. The share of the payroll in the value added creates a numerical estimate of the degree of social orientation of the state's economy. Value added is calculated as the difference between the cost of goods produced and those used in the production of materials and raw materials and accrued depreciation of equipment.

Value added and its structure determine the main objects of taxation and therefore the structure of the tax system. Value added is subject to VAT and its components are determined by the payroll and income tax objects. In Ukraine the payroll is the basis of the single social contribution and the difference between the payroll and the accrued social contribution is the basis of the personal income tax. An objective assessment of the value added makes it possible to determine the base of the three basic taxes (VAT, personal income, profit) and the single social contribution base and significantly simplify their administration.

Key words: added value, value added tax (VAT), payroll, profit, taxable object, tax base, factors of production. 